\title{
Provincial policy death-knell for iconic McCord Hospital?
}

The 103-year-old McCord Hospital in Durban, globally famous for its training and affordable high-quality healthcare, has succumbed to an external funding crisis that will almost certainly turn it into a State health facility run by the KwaZulu-Natal health department.

McCord is one of South Africa's last few government-subsidised mission hospitals (50\% province-funded). Ironically, over the last three years it reduced a R22 million accumulated loss to just R6.8 million and was headed for a vitally needed surplus. This would have enabled it to undertake a pre-National Health Insurance revamp and continue plugging the gap in the hugely under-served 'employed, uninsured' population, while delivering a service at least twice as good as any equivalent-sized public sector hospital. (McCord asks patients to pay about $40 \%$ of what they would in the private sector.)

However, 3 debilitating events overtook the financially vulnerable institution, enabling ruling politicians to press-gang it into the dominant principle of spending the bulk of taxpayers' money on 'indigent' patients. Firstly, the hospital was unilaterally taken off the list of training institutions (without being informed). Its request to be included as a partner facility in hospital-complex intern training was refused. Partly because of dwindling patient numbers and visits, McCord had begun farming its interns out to appropriate public sector hospitals for their paediatric, orthopaedic and psychiatry rotations, a common variation of a theme at many teaching hospitals. The last interns to see service at McCord left in August last year. For eight years, the United States President's Emergency Plan for AIDS relief (PEPFAR) has subsidised half the operational costs of McCord's trend-setting Sinikithemba ('We give hope') HIV/AIDS care programme - but $85 \%$ of this funding was halted in June last year. This marked the end of a 4-year (emergency) funding cycle. The United States Center for Disease Control (CDC), which administers PEPFAR, has shifted its focus from HIV Care and Treatment to HIV Prevention and Health Systems Strengthening. This means that in 


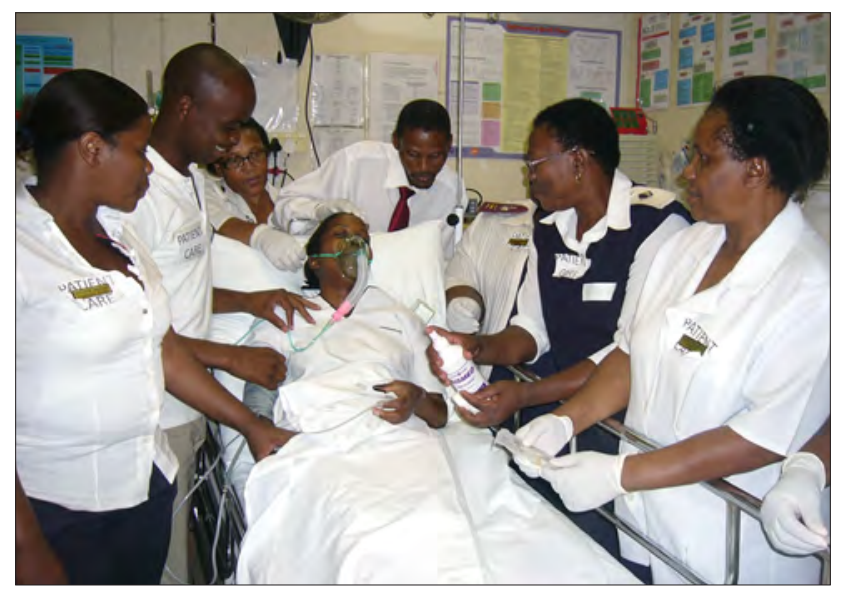

Hands-on at McCord.

future it will channel funds mainly via national governments to strengthen and co-ordinate national HIV services, instead of via those non-governmental organisations where this is lacking.

\section{Ironically, over the last three years McCord had reduced a R22 million accumulated loss to just R6.8 million and was headed for a vitally needed surplus.}

\section{Help us help you ...}

McCord's tried to persuade government to continue channelling a similar amount to Sinikithemba for operating costs, by designating it as a primary healthcare site dealing with the more complex HIV cases, but this fell on deaf ears. (National policy is HIV treatment through primary healthcare nurse-led clinics).

Explained Kevin Smith, McCord's chief financial officer: 'I think they felt that we were an expensive Rolls Royce [HIV] service in spite of our excellent outcomes and that it was not [financially] fair to the other clinics. We couldn't believe it. Discussions [with the national Department of Health] continued through April and May [last year] but the hospital simply ran out of time to find alternative options.

'We had two months to transfer out 4000 people, predominantly outpatients. Nearly 3500 of them went to the public sector HIV clinics and the others to the private sector', Smith revealed.

Tests and antiretroviral and TB drugs from the National Health Laboratory Service, provided for free after McCord was designated an official roll-out site in 2007, had topped-up Sinikithemba's 50\% PEPFAR funding. These were suddenly stopped halfway through last year. Many McCord HIV patients have continued to attend the hospital's satellite medical centre, but now fork out R300 for the HIV care consultation alone, versus R180 for the consultation, drugs and tests previously. At the time of writing, McCord was still running its male circumcision clinic and health systems strengthening team, using a 1-year cost-extension amounting to $15 \%$ of its previous year's PEPFAR funding (around R8 million per annum). McCord doctors and nurses bolster the Ethekwini (Durban) Health District's network by regularly visiting 12 rural and semi-urban clinics, primarily training primary healthcare clinic staff in the diagnosis and management of paediatric HIV, and to a lesser degree handling more complicated cases of HIV/AIDS, thus leaving the public sector nurses free to handle more 'run-of-the-mill' patients.

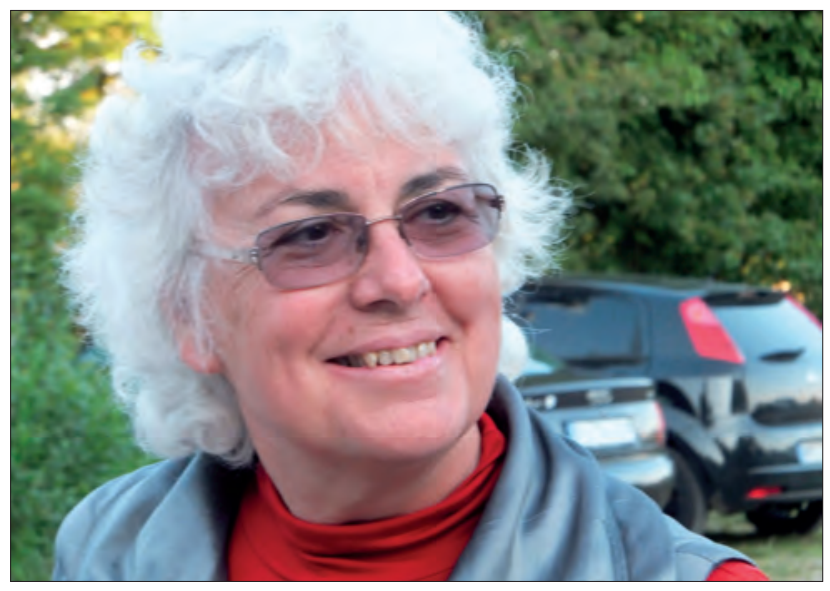

Former McCord CEO Dr Helga Holst.

\section{Coup de grâce}

The coup de grâce for McCord came when the province withdrew its $50 \%$ provincial subsidy, effective this month (March), automatically causing McCord to lose its licence to operate as a state-aided hospital. The licence and operating requirements to function as a private hospital would have required an expensive infrastructure upgrade and a radical reshaping of its operating model - now rendered unaffordable. The hospital found itself in a classic Catch-22 situation and after much agonising and exploring fund-raising options, its board finally relented in a meeting with KwaZulu-Natal premier Dr Zweli Mkhize (a former McCord intern) and his senior health department officials on the evening of 29 January this year. They accepted a staged provincial takeover pending the advice of 'transactional advisors' on McCord's finances, with input on market-related prices for its land, buildings and assets.

Some 10 days earlier, McCord management had briefed its 400 staffers about the crisis (as required by the Labour Relations Act) to enable them to seek options other than retrenchment. The upshot was that by the time the takeover was finalised (in principle), some of the best staff members had resigned and patient numbers had halved. Remaining staffers described the facility as a 'ghost hospital'.

The 142-bed hospital has a rich history and overcame seemingly overwhelming historical odds in paving the way for black medical education while situated in a former 'white-group area' (Durban's Berea). ${ }^{[1]}$ Some of the ANC's founding elite served on its board. McCord is regarded with almost universal fondness in today's top echelons of medicine, because of its high-quality training and the team approach and selfless work ethic engendered in doctors and nurses tutored there.

Smith, a highly successful former audit manager and corporate accountant, was hired as McCord CFO in 2009 and almost singlehandedly turned its finances around, primarily by re-organising the procurement network. He took over from the long-serving Dr Helga Holst, who retired in September last year and now serves as a non-executive director on the hospital board. Holst said it seemed that government officials had difficulty in embracing the concept of a 'patient contribution to their healthcare by choice' 'We've always viewed ourselves as a partner with the province in training and service provision and hugely valued them enabling us to continue our service at an affordable rate', she said. Patients chose to pay a subsidised fee and bypass other public sector services, their perception (often justified) being that they were accessing better care more easily. 
Ideology behind an 'us and them' approach?

Izindaba sources from within the plethora of angry McCord-ites, some of them current or former board members, said it seemed the provincial government mind-set was that McCord stood to make a 'profit' out of a Department of Health subsidy.

'They quite correctly say we turn away the indigent patient (true, except obviously in emergencies), but if we ever got to a surplus of income over operational expenses, it would have merely created reserves to shore us up whenever income fell away', said one. 'We need money for capital expenditure, but they can't seem to accept the concept of surpluses being reinvested ... it's almost an ideological difference in approach which rings a bit hollow. So it's maybe easiest for them to take out the exception [McCords] and not face the reality of what people wish to do with what they can afford. The irony is that if we were still making a major loss, we might still be subsidised. I guess they see us as having moved away from the mission of treating the poorest patients and having moved to the middle market, but the so-called indigent are today way better served than when our founders made their mission statement 103 years ago. Our sense of government's thinking is that if the public sector is not good enough for you, don't expect us to pay towards the cost of your healthcare.'

Meanwhile, an unseemly side-show was provided by the KwaZulu-Natal operational health chief, Dr Sibongile Zungu, who broke a mutually agreed press embargo during final negotiations to publicly and incorrectly infer financial mismanagement and inflated top-management salaries while painting a picture of elitist health services at McCord.

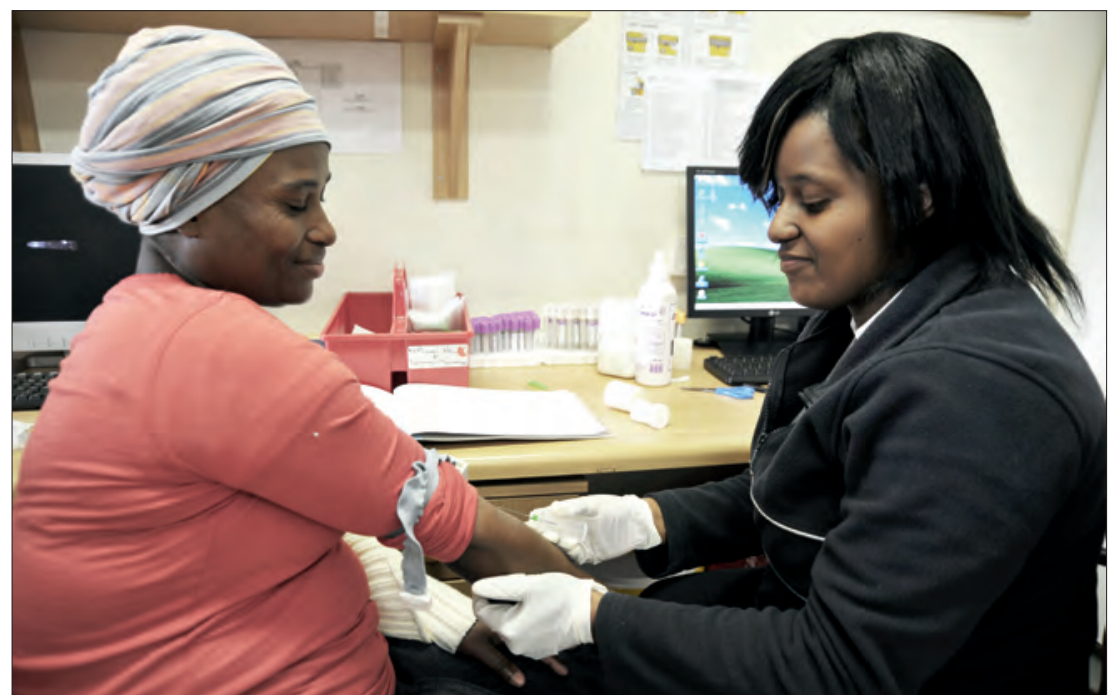

A nurse draws blood from a patient at the McCord HIV clinic.

Izindaba sources said she was later given what amounted to an 'internal' dressing down by Mkhize. While Mkhize refused to confirm this to Izindaba, his Health MEC, Dr Sibongiseni Dlomo, lent credence to the rebuke when he publicly stated that there was 'no evidence to suggest' that there might have been financial mismanagement by McCord Hospital.

Dlomo cited 'financial constraints' on government as the reason for the withdrawal of the provincial subsidy. Neither politician responded to pointed Izindaba questions on whether there had been any financial homework done on the implications of their provincial take-over, regardless of any subsidy saving, or what their timeline was for McCord's revival.

Dr Janet Giddy, who wrote McCord's first PEPFAR funding proposal and headed the hospital's HIV programme from 2003 to 2010, said they had initiated 8000 patients on ARVs and implemented pioneering prevention of mother-to-child transmission (PMTCT) care, achieving less than 3\% mother-to-child HIV transmission as early as 2004. Sinikithemba provided integrated HIV/TB and reproductive health care from 2005 and the paediatric HIV programme delivered comprehensive psycho-social support as well as clinical care. McCord clinicians were given space to use international best practice evidence to respond creatively to disease burdens: in 2008, during the provincial political victimisation of colleague Colin Pfaff at Manguzi Hospital for using externally funded AZT, just before the official roll out, her team was able to pilot innovative care programmes unhindered. As a result of the large HIV patient cohort (whose clinical data were captured on a comprehensive electronic patient record), McCord became

\section{chief}

Speaking just prior to the takeover agreement, Giddy appealed for a last-minute reinstatement of the subsidy for a finite period, to give the hospital time to make the adjustments necessary to continue its creative and innovative support of the public health sector. 'There's space for a hospital like McCord that bridges the private and public sector, especially with the NHI coming in, she argued. 'We need many sizes fitting different shapes rather than a one-size-fitsall approach. For example, in the build-up to the NHI, a lot of GPs are terrified. McCord would be a place where they could do their thing, providing affordable healthcare for a growing and forgotten cohort of patients. We have to build capacity across the spectrum or we'll fail.'

Giddy said the irony was that had the NHI been 'a bit further down the track', 


\section{IZINDABA}

alternative models such as McCord would have reaped the benefits of political support. Many top politicians and/or their families and wives in both the ruling and opposition parties have strong historical ties to McCord, either as former patients or staff. They range from President Jacob Zuma and IFP leader Chief Gatsha Buthelezi to Dr Blade Nzimande, Minister for Higher Education and Training and secretary general of the South African Communist Party.

Dr Catherine Burns, ${ }^{[2]}$ co-author of A History of McCord Hospital (due out later this year), said if the idea that state money cannot be granted to well-managed and efficient, self-run entities becomes hegemonic, 'we may all be the losers'. She said,'We have very few institutions that have survived and grown for more than a century, and even fewer that have done so with their integrity and legitimacy intact in the face of segregation and apartheid, and through the birth pangs of our young democracy. In the entire country, there is only one health institution - McCord Hospital - that can boast this legacy.

\section{Chris Bateman}

chrisb@hmpg.co.za 1. Bateman C. McCord - 100-year-old beacon of hope in turbulent health care seas. S Afr Med J
2009;99(6):424-428.
2. A historian based at the Wits Institute for Social and Economic Research, (WISER), University of the
Witwatersrand. Co-author of A History of McCord Hospital with Dr Julie Parle and Dr Vanessa Noble
of the University of KwaZulu-Natal.

S Afr Med J 2013;103(3):139-142. DOI: 10.7196/SAMJ.6806 